\title{
COMPETITION EFFECTS WITH MIXED STANDS OF WHEAT AND KOCHIA (Kochia scoparia) BIOTYPES RESISTANT AND SUSCEPTIBLE TO ACETOLACTASE SYNTHASE INHIBITOR HERBICIDES
}

\author{
P.J. CHRISTOFFOLETI \\ Departamento de Horticultura-ESALQ/USP - C.P. 9, CEP: 13418-900 - Piracicaba,SP \\ P. WESTRA \\ Colorado State University - Fort Colins-CO - 80525 - USA
}

\begin{abstract}
Greenhouse experiments were conducted to compare the competitive ability of sulfonylurea resistant and susceptible kochia (Kochia scoparia $\mathbf{L}$. Schard) compared to wheat. The results of several replacement series experiments indicate that wheat was the dominant competitor, and an average of one wheat plant reduced resistant kochia yield per plant equal to the effect of 4.8 resistant kochia or 5.4 susceptible kochia plants. Intraspecific competition was more important than interspecific competition for wheat, whereas the reverse was true for the resistant and susceptible kochia. The results of the niche differentiation index (NDI) indicate that wheat and either resistant or susceptible kochia are only partly limited by the same resources. The resistant and susceptible kochia, however, are limited by the same resources.
\end{abstract}

Key Words: weed, herbicide resistance, sulfonylurea, Kochia scoparia, weed-crop competition.

\section{EFEITOS COMPETITIVOS DA MISTURA DE STANDS DE TRIGO E BIOTIPOS DE KOCHA (Kochia scoparia) RESISTENTES E SUSCEPTIVEIS AOS HERBICIDAS INIBIDORES DA ACETOLACTASE SINTASE}

RESUMO: Experimentos foram instalados em condições de casa-de-vegetaçãocom o objetivo de comparar a capaci-dade competitiva de biotipos resistentes e suscetrveis aos herbicidas inibidores da enzima acetolactase synthase da planta daninha kochia (Kochia scoparia L. Schard) comparada com trigo. Os resultados de diversos experimentos, utilizando a metodologia chamada de substitutiva, indicaram que o trigo foj o competidor dominante, e em média uma planta de trigo reduziu o crescimento da planta de kochia resistente igual ao efeito de 4,8 plantas de kochia resistente ou 5,4 plantas de kochia suscetível. A competição chamada de intraespecífica foi mais importante que a competição interespecífica para 0 trigo, porém o inverso foi verdadeiro para os biotipos resistentes e susceptiveis de kochia. Os resultados do indice de diferenciação ecológica indicaram que trigo e qualquer um dos dois biotipos de kochia estudados foram limitados apenas parcialmente pelos mesmos recursos de crescimento. No entanto, o crescimento dos biotipos resistentes e susceptiveis de kochia foram limitados pelos mesmos fatores de crescimento. Descritores: plantas daninhas, resistência aos herbicidas, sulfonilureas, kochia, competição de plantas.

\section{INTRODUCTION}

Kochia is a major broadleaf weed in a number of crops, and specially in wheat (BLACK et al., 1969). Several herbicides are used for kochia control in wheat; however, since 1982, growers have intensively used sulfonylureas (acetolactate synthase enzyme inhibitor herbicides) for weed control on fallow area and in winter wheat (MALLORY-SMITH et al., 1990). As a consequence, biotypes of kochia resistant to sulfonylureas have been isolated from wheat fields treated with chlorsulfuron (a sulfonylurea herbicide) for five consecutive years (PRIMIANI et al., 1990).

Kochia was found to reduce wheat yield from $15 \%$ to $58 \%$ when the density of kochia varied from 4 to 70 plants $/ \mathrm{m}^{2}$, respectively (CHALLAIAH et al., 1983). No data were found in the literature on resistant and susceptible kochia biotype interference in wheat.

Replacement series experiments (a substitutive experimental design) allow the stand densities of the crop and weed to vary, but the sum 
of the crop and weed density is held constant (HARPER, 1977; PANTONE \& BAKER, 1991). Replacement series experiments have been used in weed-crop competition studies involving crop and weed; however, no paper has been found where replacement series is used to determine the competitive ability of species biotypes and crops. According to RADOSEVICH (1987), the replacement series experiment is most valuable for assessing the competitive effects of species proportion at a single total density. It is also possible to determine the relative effects of intraand interspecific interference using this design, but the partitioning of the absolute effects cannot be accomplished readily.

The specific aim of this study was to assess the influences of density and proportion on competition between wheat $\mathrm{x}$ resistant kochia biotype and wheat $x$ susceptible kochia biotype, as well as between the two kochia biotypes, using replacement series experiments performed at three differents total densities. The broader goal of the experiment was to compare the competitive ability of wheat and the two kochia biotypes to determine possible applicability to techniques and tactics of managing herbicide resistance of kochia in wheat fields.

\section{MATERIAL AND METHODS}

Kochia seeds used in the experiments were obtained from Reeder, ND, where the resistant biotype seeds were collected from cultivated fields with confirmed cases of ALS inhibitor herbicide resistance, and the susceptible biotype was collected in the vicinity of this area. The resistant and susceptible kochia seeds were tested for chlorosulfuron resistance under greenhouse conditions in 1990 and 1991, and the resistance and susceptibility of the biotypes were confirmed, were in average the commercial dosage of chlorosulfuron controlled $90 \%$ of the susceptible plants and less than $25 \%$ of the resistant biotype.

Monoculture of wheat, resistant kochia biotype, and susceptible kochia biotype were planted in $0.04 \mathrm{~m}^{2}$ (22.5 cm diameter, $25 \mathrm{~cm}$ deep) pots in the greenhouse to evaluate the responses of species and biotypes to density. Densities of 50 , 100,200 , and 400 plants $/ \mathrm{m}^{2}$ were obtained by growing 2, 4, 8, and 16 plants in separate pots. Four replicates of the monoculture density experiment were conducted as a completely randomized design.
Replacement series at total density of 100,200 , and 400 plants $/ \mathrm{m}^{2}$ were performed in $0.04 \mathrm{~m}^{2}$ (22.5 cm diameter, $25 \mathrm{~cm}$ deep) pots. The densities were obtained by planting 4,8 , and 16 plants in separate pots. Therefore, three replacement series experiments were conducted:

1) Monoculture of wheat (100:0), 75:25, 50:50, 25:75, and monoculture of resistant kochia biotype $(0: 100) ; 2)$ Monoculture of wheat $(100: 0), 75: 25$, $50: 50,25: 75$, and monoculture of susceptible kochia biotype (0:100); and 3) Monoculture of resistant kochia biotype (100:0), 75:25, 50:50, $25: 75$, and monoculture of susceptible kochia biotype (0:100). Each complete replacement series was replicated four times. Excess of seeds were planted and seedlings were thinned to desired densities within two weeks after emergence.

In all experiments, the soil used was a greenhouse potting soil. Water was provided as needed, and a balanced fertilizer was applied during irrigation watering approximately every two weeks. Plants received natural light in a photoperiod of approximately 15 hours. The average daily maximum temperature was $25^{\circ} \mathrm{C}$, and the average minimum temperature was $15^{\circ} \mathrm{C}$.

Plants were harvested at approximately 70 days of growth. The number of plants of each species and biotype in each pot at the time of harvest was recorded. The above-ground biomass was collected, dried at $90^{\circ} \mathrm{C}$ for 48 hours, and weighed.

Conventional analysis of the replacement series data (WIT \& VAN DEN BERGH, 1965) was performed qualitatively by visual interpretation of the responses of relative yield to proportion (HARPER, 1977; WIT, 1960). Relative yields for each species and biotypes were calculated as yield at each density and proportion, divided by the mean monoculture yield at that density. A statistical analysis was performed to determine whether competitive interactions occurred between the two species or biotypes. The test for competitive effects was performed using regression analysis, with relative yield as the dependent variable and density and proportion as independent variables. The null hypothesis was that observed responses did not deviate from a noninteraction of competitive equivalence line. A test for significant nonlinear fit of the data was used to indicate whether the null hypothesis could be rejected and that competition occurred between the species or biotypes.

To perform the analysis proposed by JOLLIFFE et al. (1984), data from the monoculture were evaluated first. Linear regression 
analysis on the reciprocal of total yield $(1 / Y)$ and the reciprocal of density $(1 / N)$ was conducted to estimate constant final yield $\left(Y_{\max }\right)$ and the density where yield reached $50 \%$ of the $Y_{\max }\left(K_{n}\right)$.

Projected yield $\left(Y_{p}\right)$ with no intra- or interspecific interactions was calculated from $Y_{\max }$ and $K_{n}$ obtained in the monoculture density experiment. Using data from the replacement series at 100,200 , and 400 plants $/ \mathrm{m}^{2}$ and the monoculture density data up to 400 plants $/ \mathrm{m}^{2}$, a modified replacement series diagram was constructed with plots of projected yield $\left(Y_{p}\right)$, monoculture density response $\left(Y_{m}\right)$, and replacement series yield $\left(Y_{x}\right)$. Regression equations were fit to the monoculture $\left(Y_{m}\right)$ and mixture $\left(Y_{x}\right)$ data to develop the responses for each species or biotype in the modified replacement series diagram. From these regression equations, we calculated relative monoculture or monobiotype response:

$$
R_{m}=\frac{\left(Y_{p}-Y_{m}\right)}{Y_{p}}
$$

relative species mixture response:

$$
R_{x}=\frac{\left(Y_{m}-Y_{x}\right)}{Y_{m}}
$$

The mean yield per plant from wheat and kochia biotypes from each replacement series were fit using regression analysis (SPITTERS, 1983):

- Wheat $x$ resistant kochia biotype replacement series:

$$
\begin{aligned}
& \text { Wheat }-\frac{1}{W_{w}}=A_{w}+B_{w w} * N_{w}+B_{w r} * N_{r} \\
& \text { Resistant } \rightarrow \frac{1}{W_{r}}=A_{r}+B_{r} * N_{r}+B_{r w} * N_{w}
\end{aligned}
$$

- Wheat $\mathrm{x}$ susceptible kochia biotype replacement series:

$$
\begin{aligned}
& \text { Wheat } \rightarrow \frac{1}{W_{w}}=A_{w}+B_{w w} * N_{w}+B_{w s} * N_{s} \text { (5) } \\
& \text { Susceptible }-\frac{1}{W_{s}}=A_{s}+B_{s} * N_{s}+B_{s w} * N_{w}(9)
\end{aligned}
$$

-Resistant X susceptible kochia biotype replacement series:

Sci. agric., Piracicaba, 51(2):245-251, maio/ago., 1994

$$
\text { Resistant } \rightarrow \frac{1}{W_{r}}=A_{r}+B_{r} * N_{r}+B_{r s} * N_{s}
$$

$$
\text { Susceptible }+\frac{1}{W_{s}}=A_{s}+B_{s a} * N_{s}+B_{s} * N_{r} \text { (8) }
$$

The data were also fitted to equations describing reciprocal yield responses to total density and proportion:

- Wheat $x$ resistant kochia biotype replacement series:

$$
\begin{aligned}
& \text { Wheat } \rightarrow \frac{1}{W_{w}}=A_{w}+B_{m w} * N+B_{i w} *(N * P) ; \\
& N=\left(N_{w}+N_{r}\right) ; P=\frac{N_{w}}{N}
\end{aligned}
$$

$$
\begin{gathered}
\text { Res. }-\frac{1}{W_{r}}=A_{r}+B_{n r} * N+B_{i r} *(N * P) ; \\
N=\left(N_{r}+N_{r}\right) ; P=\frac{N_{r}}{N}
\end{gathered}
$$

- Wheat $x$ susceptible kochia biotype replacement series:

$$
\begin{gathered}
\text { Wheat } \rightarrow \frac{1}{W_{w}}=A_{w}+B_{m w} * N+B_{i w} *(N * P) ; \\
N=\left(N_{w}+N_{n}\right) ; P=\frac{N_{w}}{N}
\end{gathered}
$$

$$
\begin{gathered}
\text { Sus. } \rightarrow \frac{1}{W_{s}}=A_{s}+B_{n s} * N+B_{i s} *(N * P) ; \\
N=\left(N_{s}+N_{w}\right) ; P=\frac{N_{s}}{N}
\end{gathered}
$$

- Resistant x susceptible kochia biotype replacement series:

$$
\begin{array}{r}
\text { Res. } \rightarrow \frac{1}{W_{r}}=A_{r}+B_{w r} * N+B_{i t} *(N P) ; \\
N=\left(N_{r} * N_{s}\right) ; P=\frac{N_{r}}{N} \\
\text { Sus. } \rightarrow \frac{1}{W_{s}}=A_{s}+B_{w s} * N+B_{i s} *(N * P) ; \\
N=\left(N_{s}+N_{r}\right) ; P=\frac{N_{s}}{N}
\end{array}
$$


Equations 9 to 14 simply rearrange the independent variables in 15 to illustrate interactions between density and proportions. The coefficients for intraspecific or intrabiotype competition ( $B_{w w}$, $B_{n}$, and $B_{3 s}$ ) and interspecific or interbiotype competition $\left(B_{w r}, B_{w s}\right.$, and $\left.B_{r a}\right)$ were then used to calculate relative competitive abilities (RC) for wheat and kochia biotypes, and an index for NDI differentiation:

- Wheat $\mathrm{x}$ resistant kochia biotype replacement series:

$$
R C_{w}=\frac{B_{w w}}{B_{w r}} ; R C_{r}=\frac{B_{r r}}{B_{r w}}
$$

- Wheat $\mathrm{x}$ susceptible kochia biotype replacement series:

$$
R C_{w}=\frac{B_{w w}}{B_{w s}} ; R C_{s}=\frac{B_{s s}}{B_{s w}}
$$

- Resistant X susceptible kochia biotype replacement series:

$$
R C_{r}=\frac{B_{r r}}{B_{r s}} ; R C_{s}=\frac{B_{s s}}{B_{s r}}
$$

\section{RESULTS AND DISCUSSIONS}

The yields of wheat, and of resistant and susceptible kochia biotypes are independent of the density (constant final yield response at total density of 100,200 , and 400 plants $/ \mathrm{m}^{2}$, indicating that these densities are not a significant factor in the conventional replacement series analysis. Therefore, data for all densities $(100,200$, and 400 total plants $/ \mathrm{m}^{2}$ ) were pooled to evaluate the effects of proportion. Mean total yields in monoculture over all densities were 302,1397 , and $1591 \mathrm{~g} / \mathrm{m}^{2}$ for wheat and for resistant and susceptible kochia biotypes, respectively. Regression analysis of the relative yields for each species and biotype in response to proportion indicated that the relationship was described most precisely by a quadratic equation. The significant quadratic terms (indicated by the $p$ values) suggest that relative yields for wheat versus the resistant and the susceptible kochia biotype deviated from the null response (no interaction or equivalence line) and that competition occurred between wheat and both kochia biotypes. Since the relative yield of wheat was enhanced while relative yield of resistant and susceptible kochia biotypes was suppressed, wheat was interpreted as the superior competitor. The nonsignificance of the quadratic terms for the relative yield of resistant versus susceptible kochia biotype indicates that they did not differ from the no-interaction line. The results of replacement series of resistant $x$ susceptible Kochia confirm and shows that the ability of the two kochia biotypes to interfere with the other is equivalent; i.e., each biotype contributes to the yield in direct proportion to its presence in the mixture. The maximum (constant) final yield obtained from the monoculture and monobiotype response of wheat and resistant and susceptible kochia biotypes to density (plants/ $\mathrm{m}^{2}$ ) were $367.3,1567.4$, and 1965.6 for wheat and for resistant and susceptible kochia biotypes, respectively. The equations that best represent the results of regression analysis fitting the monoculture data to a double-reciprocal model are:

$$
\begin{aligned}
\text { Wheat }- & \frac{1}{Y}=0.0029809+ \\
+ & 0.030912 *\left(\frac{1}{N}\right)
\end{aligned}
$$

$$
\begin{aligned}
\text { Susceptible }- & \frac{1}{Y}=0.000508+ \\
& +0.0222379 *\left(\frac{1}{N}\right)
\end{aligned}
$$

These curves represent results of regression analysis fitting wheat and resistant and susceptible kochia biotypes data to a doublereciprocal model:

$$
\begin{aligned}
& \text { Double reciprocal model } \rightarrow \\
& \frac{1}{Y}=\frac{1}{\left(Y_{M a x}\right)}+\left(\frac{K_{N}}{Y_{M a x}}\right) *\left(\frac{1}{N}\right)
\end{aligned}
$$

$\mathrm{Y}_{\mathrm{Max}}$ is the constant final yield, and $\mathrm{K}_{\mathrm{n}}$ is the density at which $50 \%$ of the constant final yield is approached. The $K_{n}$ densities were $38.4,24.7$, and 43.7 plants $/ \mathrm{m}^{2}$ for wheat and for resistant and susceptible kochia biotypes, respectively. Since the $K_{n}$ for susceptible biotype was less than that for wheat and resistant biotype, susceptible kochia 
biotype approached constant final yield sooner than wheat and resistant biotype as density increased. This analysis suggested that the sensitivity to intraspecific competition decreased in the following order: susceptible kochia biotype, wheat and resistant kochia biotype. The densities above which wheat, resistant kochia biotype, and susceptible kochia biotype yields were not significantly different from $Y_{\operatorname{Max}}$ were 100,200 , and 400 plants $/ \mathrm{m}^{2}$, respectively.

Projected yield $\left(Y_{p}\right)$ of each species and biotype with no intra- and interspecific competition was derived from the monoculture yield-density responses and described by the equations:

$$
\begin{aligned}
& \text { Wheat } \rightarrow Y_{p}=32.3502 * N \\
& \text { Resistant } \rightarrow Y_{p}=63.7674 * N \\
& \text { Susceptible } \rightarrow Y_{p}=44.9683 * N
\end{aligned}
$$

Monoculture yield curves were described most precisely by the double reciprocal-yielddensity models (equations 1,2 , and 3 ). These equations account for $94 \%, 83 \%$, and $89 \%$ of the variation of wheat, resistant kochia biotype, and susceptible kochia biotype yields, respectively. The mixture yields from the replacement series experiments were described most precisely by a natural $\log$ transformation of the yield:

- Replacement series wheat $\mathrm{x}$ resistant kochia biotype:

$$
\begin{aligned}
& \text { Wheat }-\ln Y_{w}=2.3024-0.0158 \text { * } \\
& N_{w}+0.000031 * N_{w}^{2} \\
& \text { Res. } \rightarrow \ln Y_{r}=1.46808+0.000666 * \\
& N_{r}+0.0000079 * N_{r}^{2}
\end{aligned}
$$

- Replacement series wheat $\mathrm{x}$ susceptible kochia biotype:

$$
\begin{array}{r}
\text { Wheat }-\ln Y_{w}=2.2076-0.01425 * \\
N_{w}+0.000027 * N_{w}^{2}
\end{array}
$$

- Replacement series resistant kochia biotype $x$ susceptible kochia biotype:

$$
\begin{array}{r}
\text { Sus. } \rightarrow \ln Y_{s}=4.8659+0.02103 * \\
N_{s}-0.000047 * N_{s}^{2} \\
\text { Res. }-\ln Y_{r}=4.7579+0.02167 \\
* N_{r}-0.000046 * N_{r}^{2} \\
\text { Sus. } \rightarrow \ln Y_{s}=4.8660 * \\
N_{s}+0.02103 * \\
N_{s}-0.000042 * N_{s}^{2}
\end{array}
$$

Relative influences of intra- and interspecific competition of yields of wheat, resistant kochia biotype, and susceptible kochia biotype show that relative monoculture and relative mixture yields varied with species and biotype proportion; therefore, contributions of intra- and interspecific competition varied with species and biotype proportion. As the proportion of wheat increased, both the influence of intraspecific competition among wheat plants and the interspecific influence of wheat on resistant and susceptible kochia biotypes increased. As the wheat proportion decreased, the influence of resistant and susceptible kochia biotypes on wheat yield (interspecific competition) was not as important as on itself (intrabiotype competition). When the two kochia biotypes were grown in a replacement series, the relative yields showed approximately the same degree of intra- and interbiotype competition. The wheat relative mixture yield showed values always very close to zero, and this indicates that the wheat prefers the kochia biotypes as neighbors to itself, and that intraspecific competition is more important than interspecific competition at any density. Resistant and susceptible kochia biotypes were suppressed more than wheat biomass whenever wheat was in the mixture.

The multispecies reciprocal yield models (equations 3 to 8) are used to graph the response of wheat or kochia biotypes to its own density for varying density of the competitor species or biotype. Responses of wheat and kochia biotypes are also graphed as the reciprocal of the yield per plant in response to total density for varying proportions of the competitor species or kochia biotypes (equations 9 to 14). For wheat, as density or proportion of kochia biotypes increased, reciprocal yield of wheat individual plants decreased; therefore, the average yield of individual plants was enhanced by increasing density or proportion 
of kochia biotypes. Reciprocal yield of kochia biotype individuals increased with increasing density or proportion of wheat; thus kochia biotypes were suppressed by increasing density or proportion of wheat. As total density increased, there was an increasing divergence of the influence of proportion. The results indicate that wheat and kochia biotypes responded best with kochia as neighbors and that this effect was enhanced as the total density increased.

The multibiotype reciprocal yield models show the response of each biotype to its own density for varying the density of the competitor biotype, and the response to total density for varying proportions of the competitor species. These results indicate that both density and proportion had the same influence on the response of the kochia biotypes. As density of one biotype increased, the reciprocal yield of the other biotype individual plants increased, and as proportion of one biotype increased, the reciprocal yield of the other biotype individual plants decreased. The results indicate that resistant and susceptible kochia biotypes responded indistinctly for either resistant or susceptible plant as neighbors.

The reciprocal yield analysis (SPITTERS, 1983; WATKINSON, 1980) provided regression equations that described the relationship of average individual plant yield and the density of wheat and kochia biotypes:

-Wheat $\mathrm{x}$ resistant kochia biotype replacement series:

$$
\begin{gathered}
\text { Wheat }-\frac{1}{W_{w}}=0.15494+0.00249 * \\
N_{w}-0.00052 * N_{r} \\
\text { Res. }-\frac{1}{W_{r}}=0.02193+0.00058 * \\
N_{r}+0.00117 * N_{w}
\end{gathered}
$$

-Wheat $x$ susceptible kochia biotype replacement series:

$$
\begin{gathered}
\text { Wheat }-\frac{1}{W_{w}}=0.16183+0.00241 * \\
N_{w}-0.00044 * N_{s}
\end{gathered}
$$

-Resistant $x$ susceptible kochia biotype replacement series:

$$
\begin{aligned}
& \begin{array}{c}
\text { Sus. }-\frac{1}{W_{s}}=0.02549+0.00050 * \\
N_{s}+0.00147 * N_{w}
\end{array} \\
& \text { Wheat }-\frac{1}{W_{r}}=0.0271+0.00058 \text { * } \\
& N_{r}+0.00072 * N \text {, } \\
& \begin{array}{c}
\text { Sus. }-\frac{1}{W_{s}}=0.02359+0.00050 * \\
N_{s}+0.00070 * N_{r}
\end{array}
\end{aligned}
$$

The coefficients for intra- and interspecific between wheat and kochia biotypes in these equations were used to calculate relative competitive abilities of wheat and kochia biotypes (equations 4.15 to 4.17 ): $\mathrm{RC}_{\mathrm{w}}=4.8, \mathrm{RC}_{\mathrm{r}}=0.50$. These ratios indicate that wheat responded similarly to 4.8 resistant kochia plants and to one wheat plant in competition, and the resistant kochia biotype responded to one wheat plant as it would to approximately 2.0 resistant kochia plants.

According to SPITTERS (1983) when the NDI exceeds the unity there is a niche differentiation. For the wheat/resistant experiment we find a value of 2.4 . So, the species are only partly limited by the same resource; they partly avoid each other. The same tendency is observed for wheat and the susceptible kochia biotype, where $\mathrm{RC}_{\mathrm{w}}=5.4 ; \mathrm{RC}_{\mathrm{s}}=0.34$; and $\mathrm{NDI}=1.85$.

For the resistant/susceptible kochia biotype experiment, there is not a niche differentiation, because the $\mathrm{NDI}=0.57$. From the descriptive equation for the per-plant biomass of susceptible kochia biotype, we derive that for susceptible biotype the presence of one resistant plant is similar to the presence of 0.57 other susceptible plants. For resistant biotype this ratio was 0.71 . The influence of a resistant plant, expressed relative to the influence of a susceptible plant, is therefore smaller for resistant biotype than for susceptible biotype. Interbiotype competition is greater than intrabiotype competition. So, the biotypes are limited by the same resources; they do not avoid each other (no niche differentiation). 


\section{LITERATURE CITED}

BLACK, C.C.; CHEN, T.M.; BROWN, R.H. Biochemical basis for plant competition. Weed Science, Champaign, v.17, p.338-344, 1969.

CHALLAIAH, A.; BURNSIDE, O.C.; JOHNSON, V.A.; ROETH, F.H.; SCHIMIDT, J.W. Identifying weed competitiveness of winter wheat cultivars. Proceedings. North Central Weed Control Conference, Urbana, v.38, p.78, 1983.

HARPER, J.L. Population biology of plants. New York: Academic Press, 1977. 892p.

JOLLIFFE, P.A.; MINJAS, A.N.; RUNECKLES, V.C. A reinterpretation of yield relationships in replacement series experiments. Journal of Applied Ecology, Oxford, v.21, n.1, p.227-243, 1984.

MALLORY-SMTTH, C.A.; THILL, D.C.; DIAL, M.J. Identification of sulfonylurea herbicide-resistantprickly lettuce (Lactuca serriola). Weed Technology, Champaign, v.4, p.163-168, 1990.

PANTONE, D.J.; BAKER, J.B. Reciprocal yield analysis of red rice (Oryza sativa) competition in cultivated rice. Weed Science, Champaign, v.39, p.42-47, 1991.
PRIMIANI, M.M.; COTTERMAN, J.C.; SAARI, L.L. Resistance of kochia (Kochia scoparia) to sulfonylurea and imidazolinone herbicides. Weed Technology, Champaign, v.4, p.169-172, 1990.

RADOSEVICH, S.R. Methods to study interactions among crops and weeds. Weed Technology, Champaign, v.1, n.3, p.190-198, 1987.

SPITTERS, C.J.T. An alternative approach to the analysis of mixed cropping experiments. I. Estimation of competition effects. Netherlands Journal of Agricultural Science, Wageningen, v.31, n.1, p.1-11, 1983.

WATKINSON, A.R. Density-dependence in singlespecies populations of plants. Joumal of Theoretical Biology, London, v.83, p.345-357, 1980.

WIT, C.T. On competition. Agricultural Research Report, Wageningen, v.66, n.8, p.1-82, 1960.

WIT, C.T.; VAN DEN BERGH, J.P. Competition between herbage plants. Netherlands Journal of Agricultural Science, Wageningen, v.13, n.2, p.212-221, 1965.

Enviado para publicação em 24.08 .93 Aceito para publicação em 22.06 .94 